\title{
A ortografia e os níveis de escrita: o erro em textos de sujeitos escolarizados
}

\section{Orthography and writing levels: mistakes within texts produced by literate subjects}

\author{
Juscelino Francisco do Nascimento* \\ Rossana Ramos Henz**
}

\begin{abstract}
RESUMO
Este artigo discute as relações entre os erros de grafia e os níveis de escrita com base na teoria da psicogênese da escrita e na análise de textos produzidos por crianças, jovens e adultos alfabetizados. A partir da ideia de que o processo de alfabetização é evolutivo e que, se não desenvolvido adequadamente para o nível alfabético ortográfico, resultará no fato de que os indivíduos, ainda que alfabetizados, cometerão incorreções na escrita de palavras, por exemplo, nos casos de homofonia interna, ou seja, fonemas idênticos marcados por diferentes grafemas; troca de fonemas surdos por sonoros; hiper e hipossegmentação; marcas de oralidade na escrita de palavras conforme a variante local; entre outras. Nosso objetivo é, portanto, demonstrar que os erros de grafia cometidos por sujeitos alfabetizados advêm de uma espécie de estagnação que ocorre no desenvolvimento da competência escrita para o nível ortográfico. As análises recaem sobre textos de adultos alfabetizados que apresentam erros de grafia, evidenciando um nível alfabético, porém não ortográfico.
\end{abstract}

Palavras-chaves: Alfabetização. Níveis de Escrita. Erros de Grafia.

Recebido em 29 de abril de 2020.

Aceito em 28 de junho de 2020.

DOI: http://dx.doi.org/10.18364/rc.2021n61.399

*UFPI/UEPB, juscelino@ufpi.edu.br, http://orcid.org/0000-0001-7090-2876

**UPE/UNICAP, rossana.ramos@upe.br, https://orcid.org/0000-0003-3369-8786

Confluência. Rio de Janeiro: Liceu Literário Português, n. 61, p. 226-248, jul.-dez. 2021 


\section{ABSTRACT}

This article discusses the relationship between spelling mistakes and writing levels based on the theory of psychogenesis of writing and the analysis of texts produced by literate children, youths and adults. Stemming from the idea that the literacy process is evolutionary and that, if not properly developed for the orthographic alphabetic level, it will result in the fact that individuals, albeit literate, will carry out writing mistakes, for example, in cases of internal homophony, that is, identical phonemes marked by different graphemes; exchange of voiceless phonemes for voiced ones; hyper and hyposegmentation; orality marks when writing words according to the local variant; among others. Our objective is, therefore, to demonstrate that spelling mistakes made by literate subjects come from a sort of stagnation that occurs in the development of written competence for the spelling level. The analyses focus on texts, which present spelling mistakes, written by literate adults, hence evincing an alphabetic but not orthographic level.

Keywords: Literacy. Writing Levels. Spelling mistakes.

\section{Introdução}

Neste artigo, apresentamos discussões sobre a questão dos erros de grafia cometidos por indivíduos adultos alfabetizados como sendo uma espécie de "parada" na aprendizagem da ortografia, pelo fato de que esse conhecimento é evolutivo, ou seja, deve ocorrer ao longo das etapas de escolarização. A questão é que cometer esses erros produz atitudes linguísticas negativas na sociedade e até mesmo por parte de professores de Língua Portuguesa que, muitas vezes, alegam não saber como solucionar o problema, conforme observamos em Morais (2010, p. 9):

\footnotetext{
Discutir ortografia é enveredar por um espaço de controvérsias, pois implica enfocar um objeto marcado por preconceitos. Por um lado, existem pessoas que continuam dando à questão ortográfica um peso não só desproporcional, mas também distorcido. Refiro-me a professores e outros cidadãos que têm postura persecutória ante os alunos (ou usuários da língua que já saíram da escola) quando cometem erros ortográficos.
}

Confluência. Rio de Janeiro: Liceu Literário Português, n. 61, p. 226-248, jul.-dez. 2021 
No senso comum, existem diversas hipóteses que podem justificar esse tipo de problema. Entre elas, destacamos fatores como a complexidade do sistema ortográfico, a falta de leitura, a desatenção no ato da escrita, ou até mesmo a escrita teclada no meio digital, sobretudo em chats ouredes sociais, quando várias pessoas conversam ao mesmo tempo, demandando certa rapidez na escrita, implicando o uso de abreviaturas, início de frases com letra minúscula, falta de acentuação em palavras e outras "incorreções".

De certo que os estudos sobre erros de grafia têm origens variadas, não podendo ser atribuídas a somente um dos fatores acima expostos, mas a um conjunto de situações, entre elas, questões de natureza pedagógica que, a nosso ver, seria a mais provável. No que se refere, por exemplo, à falta de leitura, podemos inferir que, de fato, o contato com o texto escrito pode auxiliar o conhecimento da grafia. Todavia, segundo Zorzi (s/d, p.1):

(...) a prática clínica tem mostrado que esta relação entre frequência de escrita e domínio da ortografia não parece tão automática ou simples. É possível encontrar crianças que leem ativamente, que gostam de ler e que, mesmo assim, apresentam dificuldades em relação a escrever palavras, revelando que, embora elas vejam as palavras impressas de uma determinada forma, elas escrevem a mesma palavra de outra maneira, fazendo substituições de letras, por exemplo.

Quanto à falta de atenção, pode-se observar que, mesmo em textos escritos ou reescritos em situação de maior monitoramento, como provas, resenhas, resumos etc., por alunos do Ensino Fundamental, Médio e Superior, os erros de grafia persistem, o quedemonstra o desconhecimento de determinadas regras e não apenas distração.

Sobre a escrita no meio digital, compreendemos se tratar de um contexto específico em que os sujeitos escrevem dessa ou daquela maneira, dependendo do gênero ou do suporte. Por exemplo, ao enviar um e-mail de 
trabalho, certamente se empreenderá uma escrita mais formal do que em uma mensagem de whatsapp a um amigo. Em pesquisa realizada por Gomes e Correa (2009), com adolescentes usuários de redes sociais, foi observado que o uso da "linguagem teclada", ou seja, aquela considerada descontraída, com marcas de oralidade, não ocorre em escritos escolares como cadernos, provas etc.. Assim sendo, podemos inferir que o uso desse tipo de escrita não implica desaprender as normas de grafia.

Quanto à complexidade do sistema ortográfico da língua, existe, de fato,certa dificuldade quando no início do processo de alfabetização, uma vez que as crianças tendem a escrever como falam (KATO, 1986). A questão se dá em virtude de que, antes de entrarem em contato com a escrita alfabética, os falantes de uma língua não analisam ainda as sílabas em segmentos, mas, sim, de forma holística (ABAURRE, 2001). Todavia, ao longo do tempo, com base na prática de escrita monitorada pelas intervenções pedagógicas, $\mathrm{O}$ problema vai sendo superado.

Desse modo, o que se pode inferir é que se o indivíduo domina as regras ortográficas, bem como tem dúvida quanto à ortografia de uma palavra desconhecida, dificilmente cometerá incorreções. O que se entende, portanto, é que os erros de grafia cometidos por adultos alfabetizados, segundo nosso postulado nesse artigo, advêm de uma espécie de "parada" em um nível em que o usuário da língua estrutura a escrita segundo suas próprias hipóteses e não pelas impressões do mundo externo, ou seja, segundo as normas ortográficas, o que, certamente, demonstra que essas regras não foram aprendidas. Para Barbosa (1994, p. 73):

A Psicogênese pressupõe a criança como um sujeito cognoscente, um sujeito que constrói ativamente o saber. Segue-se então que, para serem incorporadas à estrutura cognitiva, as informações percebidas no mundo exterior devem ser transformadas pelo esquema de assimilação do sujeito, através de um processo de reestruturação das hipóteses já elaboradas pelo sujeito da aprendizagem. 
Com isso, afirmamos que, durante o processo de aquisição do sistema alfabético, o sujeito passa por situações de conflito em que ocorrem comparações entre aquilo que sabe (hipótese) e a forma convencional da escrita.

Desse modo, no decorrer da exposição, discutiremos os erros que cometem os sujeitos jovens e adultos, após o período sistemático da alfabetização, quando a escrita não é mais somente um elemento de interação, mas também uma forma de avaliação social, isto é, quando os erros de grafia comprometem negativamente os indivíduos em suas práticas sociais.

A metodologia utilizada nessa pesquisa envolve a apresentação de discussões teóricas, bem como a análise de três textos produzidos por uma criança e dois adultos alfabetizados em situações funcionais de escrita: a reprodução de uma história, uma carta de ameaça e uma prova de Sociolinguística, aplicada no Curso de Letras da Universidade de Pernambuco (UPE). O método qualitativo respalda a análise dos microprocessos que envolvem a pesquisa.

\section{Estudos teóricos}

Do ponto de vista metalinguístico, o processo de construção da linguagem escrita implica compreender e produzir ideias, bem como aprender a refletir sobre a linguagem como objeto constituído por normas internas (as hipóteses) e externas (as normas). Em uma espécie de jogo em que se empreendem aspectos linguísticos, cognitivos e sociais, a escrita apresenta-se como alvo de pensamento e manipulação. Para Fayol (2014, p. 24):

(...) a escrita se organiza em três níveis: [...] a preparação do conteúdo da mensagem em função da situação e do destinatário; a formatação linguística (léxico, sintaxe, formas ortográficas, organização retórica do texto); a execução motora.

Com isso, podemos vislumbrar um campo em que se discute a escrita sob a égide de vários conhecimentos, entre eles, as percepções de mundo, 
assim como as técnicas que são empreendidas no ato de escrever. Entretanto, nesse processo, podem ocorrer desvios/erros que impliquem a incompreensão ou deturpação do sentido pretendido, não só por falha de quem escreve, mas pelo fato de que do outro lado de quem escreve tem alguém que lê e que pode fazer diversas interpretações.

A questão dos erros de escrita, vista pela concepção do alfabetismo, segundo Soares (2013), consiste no fato de que, após o indivíduo ser alfabetizado (aprender a decodificar), deveria desenvolver conhecimentos e habilidades para produzir textos, desde os mais simples, como a escrita do próprio nome, até os mais complexos, como uma tese de doutorado. No entanto, na prática, isso não procede com todas as pessoas que são alfabetizadas, o que evidencia que há níveis de alfabetismo.

Teoricamente, ao longo da escolarização, a competência para a escrita é ampliada e o indivíduo pode (deve) chegar ao nível alfabético. Em uma espécie de evolução de níveis, as criançasvão desenvolvendo as habilidades cognitivas e metacognitivas, sendo capazes de traduzir fonemas em grafemas, utilizar as normas ortográficas, a pontuação, o vocabulário adequado, entre outros recursos linguísticos.

Além dessas questões relacionadas à forma, deverão selecionar e organizar as ideias, expressando-as adequadamente, conforme indica a Base Nacional Comum Curricular - BNCC (2017, p.78):

Utilizar, ao produzir textos, os conhecimentos dos aspectos notacionais - ortografia padrão, pontuação adequada, mecanismos de concordância nominal e verbal, regência verbal etc., sempre que o contexto exigir o uso da norma-padrão.

Contudo, o que vem sendo observado na prática é que grande parte dos alunos que terminam o Ensino Médio (66\%) ainda não apresentam níveis de proficiência para a leitura e escrita, conforme dados do Indicador de Alfabetismo Funcional (2018). 
Segundo Antunes (2008), isso ocorre em virtude de os estudos linguísticos ainda não terem chegado à escola de forma efetiva. Há certa confusão na forma como se vê a língua, a linguagem e a gramática, fato agravado pelas pressões sociais e pela cobrança da sociedade por se falar e escrever a "língua correta".

\subsection{A aprendizagem da escrita}

Segundo Gombert (2003), a criança apresenta sua capacidade metalinguística desde muito cedo. De modo espontâneo, ela é capaz de manipular a linguagem sob a forma de compreensão e produção. Contudo, esta manifestação é, por motivos de clareza, distinta pelo autor em duas formas: a epilinguística, que se evidencia, sendo a criança ainda muito pequena -2 a 3 anos - por meio de autocorreções; e a metalinguística,que resultam das aprendizagens explícitas, quase sempre resultado da dinâmica escolar.

Contrariamente às habilidades epilinguísticas, que se formam em paralelo ao desenvolvimento linguístico natural da criança, a habilidade metalinguística se instala em paralelo à leitura. Isto é, a aprendizagem da escrita e da leitura difere radicalmente da aquisição da linguagem oral,a qual depende, unicamente, de programas inatos, processos biologicamente determinados, que se ativam imediatamente a que o bebê entre em contato com o ambiente de fala, o que não implica um conhecimento - ter consciência - da estrutura formal (fonológica e sintática) de sua língua.

Segundo Barrera (2003, p. 65):

[...] Existe uma grande preocupação no campo da pesquisa em alfabetização, a respeito das relações entre o desenvolvimento das habilidades metalinguísticas e a aprendizagem da língua escrita. A aprendizagem da leitura e da escrita em um sistema alfabético, isto é, que se utiliza de símbolos gráficos para representar os sons da fala, pressupõe que esta última, utilizada de forma natural e eficiente pela criança nas situações comunicativas do dia-a-dia, passe a ser objeto 
de uma reflexão deliberada, ou seja, que a criança desenvolva o que se costuma denominar consciência ou capacidade metalinguística.

O que denominam os autores como sendo capacidade metalinguística é a habilidade para segmentar e manipular a fala em suas diversas unidades - palavras, sílabas e fonemas; para separar as palavras de seus referentes significado e significante; para perceber as semelhanças e diferenças sonoras; para julgar coerência sintática e semântica, entre outras.

$\mathrm{Na}$ discussão sobre as relações entre a alfabetização e a capacidade metalinguística, há um ponto que tem gerado controvérsia entre os estudiosos do tema: para se alfabetizar, a criança necessita de certa consciência metalinguística ou a consciência metalinguística é consequência da alfabetização? A abordagem teórica que tem se mostrado mais coerente é a que considera que há um processo interativo, ou seja, uma influência mútua de um processo sobre o outro.

Dentre os processos metalinguísticos que se observam na aquisição da língua escrita, destacam-se, segundo Barrera (2003), a consciência fonológica, a consciência lexical e a consciência sintática. A consciência fonológica é a habilidade utilizada para analisar a linguagem oral de acordo com as unidades sonoras constituintes. A consciência lexical diz respeito à habilidade de identificar as palavras, ou seja, de segmentar o discurso em unidades lexicais, considerando suas características morfológicas e semânticas, enquanto a consciência sintática refere-se à habilidade do indivíduo com a estrutura gramatical das sentenças. Mediante um número ilimitado de unidades lexicais, ele seria capaz de compor, a partir da escolha dessas unidades, enunciados que façam sentido, assim como seria capaz de compreendê-los.

Entendida, nesta perspectiva, como condição ou ferramenta para a alfabetização, a metalinguagem, principalmente no campo teórico da Psicolinguística, não se encerra nos tipos de "consciência" acima descritos. Ainda em Barreira (2003), encontramos a ideia de que a linguagem não se restringe a simples processos de codificação/decodificação, considerados 
isoladamente, a partir das relações entre letras e sons. Para ler e escrever bem, é necessário ir além dos aspectos morfológicos e sintáticos do texto, implicando, sobretudo, aspectos de natureza extralinguística, ou seja, o chamado conhecimento de mundo.

$\mathrm{O}$ que se pode inferir deste processo é que a metalinguagem como instrumento de leitura e escrita está além da chamada consciência metalinguística. Também neste campo em que se incluem questões de natureza cognitiva, pode-se afirmar que a língua, ainda que em processo de aquisição pelo indivíduo, está intrinsecamente ligada aos vetores sóciohistórico-culturais que sobre ela recaem. $\mathrm{O}$ fato de uma criança aprender esta palavra e não aquela, de adquirir um determinado sotaque, de aproveitar-se de um determinado contexto para "adivinhar" uma palavra, demonstra o caráter social da língua.

Com base na teoria epistemológica de Piaget e utilizando os resultados da psicolinguística contemporânea como marco de referência, nos anos 1970, as pesquisadoras Ferreiro e Teberosky (1986) desenvolveram estudos que evidenciaram uma nova perspectiva que resultou no interesse de psicólogos e pedagogos, os quais vislumbraram uma nova aplicação da teoria de Piaget a um domínio inexplorado, o da lecto-escrita. A questão envolveu também os psicolinguistas no que diz respeito às relações entre conhecimento linguístico e compreensão da língua escrita, bem como aos epistemólogos dedicados a estudar os processos de construção do conhecimento. Por fim, essa abordagem atingiu os educadores interessados em compreender quais são os processos mentais das crianças, ou seja, o que de fato ocorre fora da visão estreita dos métodos.

Conforme Ferreiro e Teberosky (1986), os processos de aprendizagem da lecto-escrita não dependem de métodos, mas da própria atividade do sujeito. Desta forma, o trabalho das pesquisadoras inicia pelo interesse em descobrir qual era o processo de construção da escrita. Para tal, em situação experimental, buscaram um modelo de pesquisa em que a criança colocasse em evidência a escrita e a leitura do modo exato como as vê. Além disso, 
as autoras observaram os conflitos e os problemas que a própria criança propõe para si ao escrever.

O propósito deste processo era o de descobrir as hipóteses que a criança formulava, à luz de seu próprio conhecimento, segundo as tarefas propostas. Em todas as tarefas, no entanto, eram introduzidos elementos conflitivos - ou ao menos potencialmente conflitivos -, cuja solução requeria, por parte da criança, um raciocínio real.

$\mathrm{O}$ resultado dessa pesquisa revelou e estabeleceu duas novas perspectivas para o campo da aquisição da lecto-escrita. A primeira, de que o processo de aprendizagem da criança pode vir de caminhos insuspeitados; a segunda, de que as crianças, ao chegarem à escola, já dominam conhecimentos sobre a escrita, não começando do zero, como supõem os métodos tradicionais. Também frutos desta investigação, evidenciaram-se etapas ou níveis (hipóteses), pelos quais a criança (sujeito cognoscente) passa durante a sua trajetória de construção da escrita e da leitura, conforme expomos a seguir.

\subsection{Níveis de escrita}

Os estudos de Ferreiro e Teberosky (1986) informam que, no nível pré-silábico, não se busca correspondência com o som; as hipóteses das crianças são estabelecidas em torno do tipo e da quantidade de grafismo. A criança tenta, nesse nível, diferenciar o desenho da escrita, ainda que a escrita sejam garatujas; utilizar no mínimo duas ou três letras para poder escrever palavras; reproduzir os traços da escrita, de acordo com seu contato com as formas gráficas (imprensa ou cursiva), escolhendo a que lhe é mais familiar para usar nas suas hipóteses de escrita; variar os caracteres para obter palavras diferentes.

O nível silábico pode ser classificado por Silábico e Silábico Alfabético: no primeiro, a criança compreende que as diferenças na representação escrita estão relacionadas com o "som" das palavras, o que a leva a sentir a necessidade de usar uma forma de grafia para cada som. 
Assim, ela utiliza os símbolos gráficos de forma aleatória, usando apenas consoantes, apenas vogais ou letras inventadas, repetindo-as de acordo com o número de sílabas, como por exemplo, RAF, para BONITA. No segundo, sendo também marcada a quantidade de sílabas da palavra, já são utilizados grafemas correspondentes aos fonemas, como por exemplo, AEA, para a palavra JANELA ou CVL, para CAVALO. Sobre o nível silábico-alfabético, as autoras postulam que a criança entende que as sílabas podem ser compostas por uma ou mais letras, dependendo da quantidade de fonemas que compõem as palavras, todavia ainda sem o devido atendimento às normas ortográficas.

Nessa perspectiva, conforme Ferreiro (1985, p.13-14), as crianças:

[...] vão desestabilizando a hipótese silábica até que [...] têm coragem suficiente para se comprometer em seu novo processo de construção. O período silábico-alfabético marca a transição entre os esquemas prévios em vias de serem abandonados e os esquemas futuros em vias de serem construídos. Quando a criança descobre que a sílaba não pode ser considerada como unidade, mas que ela é, por sua vez, reanalisável em elementos menores, ingressa no último passo da compreensão do sistema socialmente estabelecido. E, a partir daí, descobre novos problemas: pelo lado quantitativo, se não basta uma letra por sílaba, também não pode estabelecer nenhuma regularidade duplicando a quantidade de letras por sílaba (já que há sílabas que se escrevem com uma, duas, três ou mais letras); pelo lado qualitativo, enfrentará os problemas ortográficos (a identidade de som não garante a identidade de letras, nem a identidade de letras a de som).

Embora a sílaba não seja mais considerada uma unidade e que pode ser separada em unidades menores, a escrita se constitui conforme as hipóteses até então construídas e não segundo as normas ortográficas, ou seja, a identificação do som não é garantia da identificação da letra, o que pode gerar as ditas dificuldades ortográficas. Nessa etapa, podem ocorrer erros/ desvios como: a) omissão de grafemas: CADERA por CADEIRA; PATO por PRATO; ARMIO por ARMÁRIO etc.; b) troca de fonemas surdos por 
sonoros e vice-versa: POTE por BOTE; DUDO por TUDO; FARA por VARA etc.; c) omissão de grafemas sem valor sonoro: QERO por QUERO (dígrafos), ORA por HORA etc.; d) troca de posição das letras: BURXA por BRUXA; BIANA por BAIANA etc.; e) Acréscimos de letras: PRRATO por PRATO; BANNANA por BANANA; OURELHA por ORELHA etc. Aliado a isso, é preciso atentar para o fato de que alguns casos podem ser considerados não como desconhecimento da escrita, mas como transcrição de determinadas variantes da fala, como UVEIA por OVELHA, CUCUI por CUSCUZ.

No nível alfabético com falhas, os alfabetizandos já apresentam, em sua escrita, uma preocupação mais ampliada com a análise fonética das palavras. Contudo, ainda ocorrem falhas, tendo em vista o grau de conhecimento da ortografia e a amplitude da consciência metalinguística dos sujeitos. Em se tratando da consciência metalinguística de uma ação cognitiva que faz "pensar" sobre as formas linguísticas, ou seja, que impõe ao sujeito uma reflexão sobre o uso da língua, entendemos que possa ser essa consciência um auxílio importante para a fala e a escrita. Para Scliar-Cabral (1995), a consciência metalinguística envolve a reflexão sobre os níveis fonológico, sintático, semântico e pragmático.

No nível alfabético-ortográfico, a escrita é empreendida segundo as normas ortográficas, ou seja, o indivíduo é capaz não somente de escrever corretamente, mas, sobretudo, de buscar essas formas no caso de desconhecer a escrita de uma palavra. Os fatores que influenciam essa competência para a escrita ortográfica são de várias naturezas. Para Queiroga, Borba eVogeley (2004), o aprendizado da ortografia requer, dentre outras capacidades, o correto processamento das informações fonológicas e o desenvolvimento da consciência metalinguística no que se refere ao conhecimento gramatical, bem como a exposição contínua e formal ao material escrito.

Há de se considerar relevante também, nesse processo, a frequência de aparecimento das palavras nas práticas de fala e escrita do indivíduo, isto é, palavras conhecidas tendem a ser grafadas corretamente. Em nossa perspectiva, consideramos que, aliados aos processos cognitivos que levam à 
escrita ortográfica, devem ser considerados fatores de natureza pedagógica, ou seja, estratégias didáticas adequadas desenvolvidas pelos professores podem contribuir para o alcance do nível ortográfico ainda no ensino fundamental, conforme citado pela Base Nacional Curricular Comum (2017).

Para Moraes (2010, p.28):

Dada a sua natureza de convenção social, o conhecimento ortográfico é algo que a criança não pode descobrir sozinha, sem ajuda. Quando compreende a escrita alfabética e consegue ler e escrever seus primeiros textos, a criança já apreendeu o funcionamento do sistema de escrita alfabética, mas ainda desconhece a norma ortográfica. Esta é uma distinção importante para entendermos por que os alunos principiantes cometem tantos erros ao escrever seus textos e por que temos que ajudálos na tarefa de aprender a "escrever segundo a norma.

Nessa perspectiva, entendemos que a aprendizagem da escrita alfabético-ortográfica dificilmente é alcançada de modo individual, mas, na maioria das vezes, por um processo de intervenção pedagógica que auxilia a apreensão das normas da escrita.

\subsection{A questão do erro}

Os chamados erros de escrita por uma questão metodológica são, geralmente, analisados em categorias, conforme os propósitos da investigação. A esse respeito, conforme Bortoni-Ricardo (2005, p. 54):

[...] encontramos quatro categorias: erros decorrentes da própria natureza arbitrária do sistema de convenções da escrita; erros decorrentes da interferência de regras fonológicas categóricas no dialeto estudado; erros decorrentes da interferência de regras fonológicas variáveis graduais; erros decorrentes da interferência de regras fonológicas variáveis descontínuas.

O que se observa nessas categorias é uma visão focada principalmente na questão fonológica, ou seja, os erros de grafia seriam decorrentes das

Confluência. Rio de Janeiro: Liceu Literário Português, n. 61, p. 226-248, jul.-dez. 2021 
relações entre fala e escrita, em que se incluem as variáveis entre essas duas modalidades da língua. Segundo Souza e Vale (2017, p. 4):

\begin{abstract}
$\mathrm{Na}$ escrita de uma dada palavra, muitas vezes, recorre-se ao conhecimento específico de escrita dessa palavra. Se o formato escrito da palavra é desconhecido, recorre-se à representação fonológica e ao conhecimento de regras e regularidades de transcrição dos "sons" (i.e., se ouço o /R/ entre vogais, escrevo $<$ rr $>$ como em carro). O conhecimento da escrita na sua dimensão ortográfica tem quer uma dimensão de imagem mental da palavra escrita, quer uma dimensão de consciência de regularidades e padrões combinatórios ortográficos que possibilitam a escrita das palavras de acordo com a norma ortográfica. O conhecimento ortográfico é o conjunto de conhecimentos - representação mental das palavras escritas e conhecimento das combinações possíveis e impossíveis de um dado sistema de escrita-mobilizado para a escrita correta de palavras.
\end{abstract}

Para Cagliari (2003), além das categorias descritas por BortoniRicardo (2005), os erros de escrita implicam a transcrição fonética, uso indevido de letras, hipercorreção, modificação da estrutura segmental das palavras, juntura e segmentação, forma morfológica diferente, forma estranha de traçar as letras, uso indevido de letras maiúsculas ou minúsculas, acentos gráficos, sinais de pontuação e problemas sintáticos.

É importante ressaltar que, de acordo com Cagliari (2003), erros ortográficos são naturais no processo de aquisição da linguagem e decorrem das atitudes individuais que evidenciam as reflexões e conhecimentos formulados sobre a escrita. $\mathrm{O}$ autor afirma que as incorreções ortográficas, portanto, não devem ser avaliadas como erros, mas como tentativas de acerto. De certo que essa ideia aplica-se aos sujeitos até um determinado estágio de escolarização, tendo em vista que os Parâmetros Curriculares Nacionais (1998, p.63):

[...] preveem que ao final do Ensino Fundamental os alunos possam estar aptos à utilização das regularidades observadas em paradigmas morfológicos como parte das estratégias de solução de problemas de ortografia e de acentuação gráfica.

Confluência. Rio de Janeiro: Liceu Literário Português, n. 61, p. 226-248, jul.-dez. 2021 
Compreendemos, assim, que é necessário conhecer a ortografia, a qual, segundo Cagliari (1998, p. 123). "[...] é mais importante do que a simples ideia de um alfabeto no nosso sistema de escrita, porque ela controla a categorização gráfica e funcional, muito mais do que o princípio alfabético."

$\mathrm{O}$ autor segue afirmando que ortografia congela o modo de escrever, neutralizando as formas de transcrição fonética e as variantes dialetais, possibilitando a decifração da linguagem para todos os falantes de uma língua.

Para Morais (2007, p.27),

[...] a ortografia é uma convenção, uma invenção histórica necessária para suprir limitações da notação alfabética e que constitui em si um objeto de conhecimento, o que, em nossa concepção, exige que seja ensinada de modo sistemático na escola.

Quando o autor afirma que a ortografia deve ser ensinada de modo sistemático na escola, compreendemos que o conhecimento das normas ortográficas implica uma análise atenta por parte dos indivíduos quando escrevem as palavras, prática que deve ser incentivada pelo professor frequentemente. Somente corrigir as palavras no texto e devolvê-lo ao aluno não é uma estratégia eficiente. É preciso evidenciar as particularidades da escrita, observando as caraterísticas da ortografia da língua. Faz-se importante, por exemplo, discutir a homofonia - fonemas representados por vários grafemas como SS, Ç, S, SC ou J e G etc. -; regras de acentuação; as normas que advêm da etimologia da língua e, ademais, as relações entre os modos de pronunciar as palavras (variantes) e de escrevê-las.

Ainda do ponto de vista pedagógico, a ortografia pode ser objeto de jogos e atividades lúdicas que chamem atenção para a escrita das palavras. Cruzadinhas, forca, entre outros podem ampliar a consciência metalinguística, fazendo com que os alunos percebam e busquem, por meio de perguntas, ou em instrumentos como o dicionário, as formas ortográficas da escrita das palavras. 


\section{Análise}

Para efeito de análise, selecionamos três produções textuais que evidenciam questões de ortografia a serem observadas. Trata-se da escrita de sujeitos em diferentes níveis de escolarização, bem como de conhecimento da ortografia. O material pertence ao acervo pessoal dos pesquisadores.A imagem, a seguir, mostra-nos a escrita de uma criança que se encontra no nível alfabético dito com falhas, em que observamos erros de grafia das palavras:

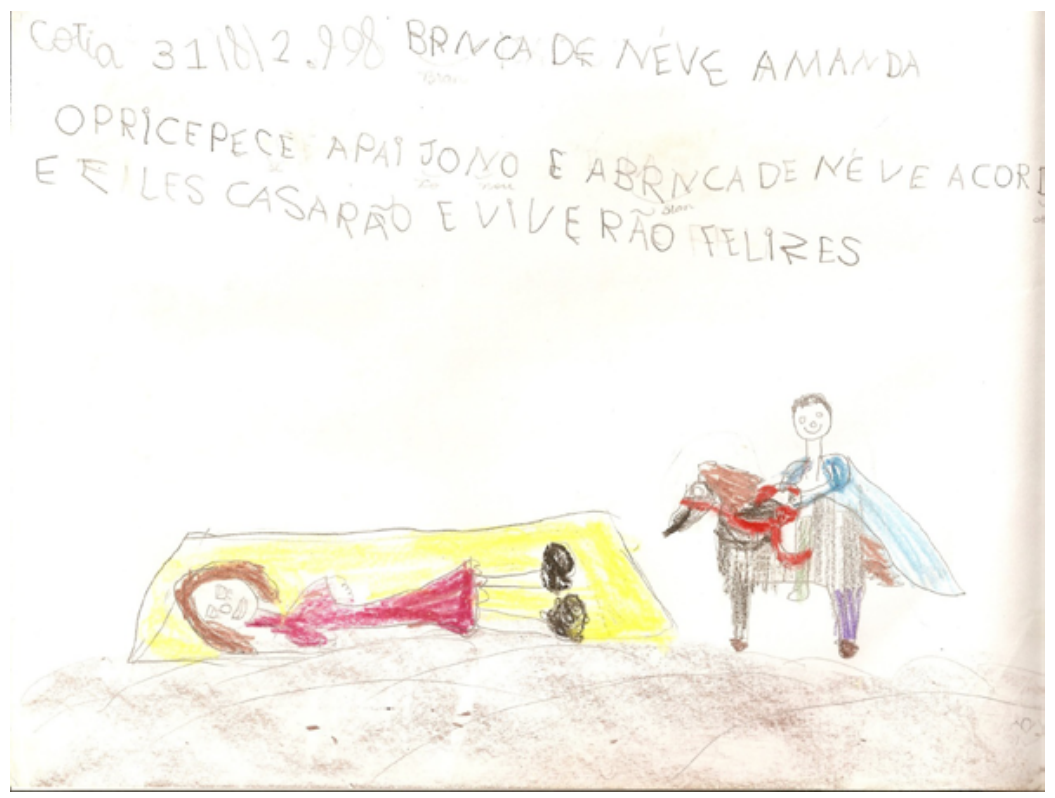

Figura 1. Produção I

\section{Legenda:}

Texto de uma criança de seis anos, contando a história de Branca de Neve.

BRANCA DE NEVE AMANDA. OPRICEPECE APAIJONO E ABRNCA DE NEVE ACORDO E E LES CASARÃO E VIVERÃO FELIZES. 


\section{Análise:}

O que se observa no texto da Figura I são questões comoa) hipossegmentação e hipersegmentação ${ }^{1}$ (delimitação de palavras) em OPRINEPECE e E LES; b) omissão de letras (PRICEPE); c) inversão de letras na palavra (ABRNCA - nesse caso, poderíamos também considerar que houve hipossegmentação em A BRANCA); d) troca de letras (X por J em APAIJONO); e) a omissão do U final no verbo APAIJONO e ACORDO em virtude da pronúncia da palavra; f) a troca do final AM (passado do verbo) pelo ÃO (futuro).

Em período alfabético com falhas, a criança, por conta da idade (6 anos), expressa-se por meio do desenho e da escrita. Considerando-se a faixa etária e o tempo de escolarização ( $1^{\circ}$ ano do Ensino Fundamental), podese avaliar sua escrita como bastante desenvolvida. As questões de escrita ortografia, com as devidas intervenções, serão futuramente sanadas.

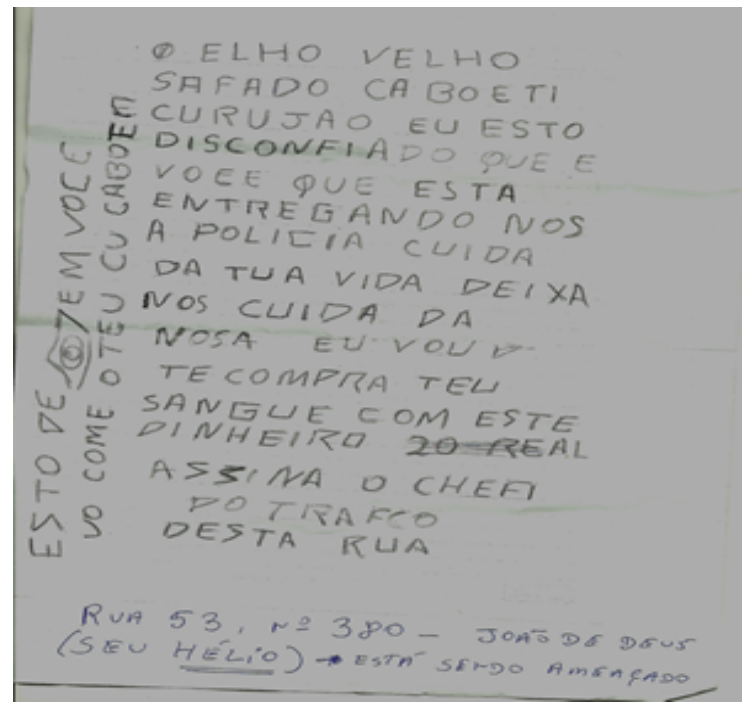

Figura 2. Produção II

1 Denomina-se hipersegmentação quando as palavras são escritas segmentadas como na Figura I. E LES (ELES). A hipossegmentação caracteriza-se quando se juntam palavras como em ABRANCA (A BRANCA). 


\section{Legenda:}

Texto produzido por um adulto alfabetizado com a intenção de ameaçar um morador do bairro.

\begin{tabular}{|l|}
\hline O ELHO VELHO \\
SAFADO CABOETI \\
CURUJAO EU ESTO DISCONFIADO QUE E \\
VOCE QUE ESTA \\
ENTREGANDO NOS \\
A POLICIA CUIDA \\
DA TUA VIDA DEIXA \\
NOS CUIDA DA NOSA \\
EU VOU TE COMPRA TEU SANGUE COM ESTE DINHEIRO 20 REAL \\
ASSINA O CHEFI DO TRAFCO DESTA RUA \\
ESTO DE (DESENHO DE UM OLHO) EM VOCE VO COME TEU CU \\
CABOETEN
\end{tabular}

A escrita do texto demonstra que o sujeito é alfabetizado e, embora não tenhamos a informação precisa, deve ter cursado pelo menos o Ensino Fundamental. Isso se justifica por apresentar conhecimentos suficientes para caracterizar sua produção como sendo do gênero carta anônima, já que constam aí elementos como vocativo, identificando o destinatário (ELHO, VELHO SAFADO), e a assinatura caracteriza-o apenas como CHEFI DO TRAFCO.

A linguagem utilizada também se adéqua ao gênero - ameaça -, já que, com o intuito de amedrontar o destinatário, o autor faz uso de vocábulos de alta expressividade como, por exemplo, do palavrão e do desenho na lateral do texto para reforçar que "está de olho" no destinatário. A letra de forma é outra característica do anonimato.

Por um lado, podemos, a partir desses elementos, compreender que "o recado foi dado", ou seja, o texto produz o efeito desejado pelo autor, evidenciando sua competência em cumprir a tarefa desejada. Por outro lado, seus conhecimentos sobre a ortografia demonstram o desconhecimento sobre 
as regras. Nessa perspectiva, ocorrem a) troca de letras - I por LH (consoante lateral palatal, em HÉLIO, grafado ELHO;b) escrita fonética (CABUETI/ AUCAGUETE - DISCONFIADO/DESCONFIADO - CHEFI/CHEFE), ou seja, escrita conforme a variante linguística; c) omissão do $\mathrm{R}$ final dos verbos no infinitivo, falta de acentos, falta de pontuação; d) omissão da letra na palavra TRÁFICO.

A turia variacionista o sufuto deperuve a faba

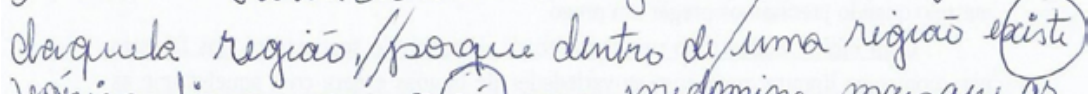
várias linguagens, mais uma predomina mas que as outras. Tem pissas qui ehfigo en uma regiá falando um veri perdendo o sutaque eadquirinots outro da regiaz. A tearia interacionista 0 sefeito disereve a relocaco da fola entre as pessoas, on se fa, a interacao como ill se interagem mesmo quando haven divercidode de linguas. Ima retaçá /entre propessor e alumo, para que scanteca uma compreenpaó onelhor, o professor deve prourar mio que o fluno naĩ se prefudique. I Poitanto a interacai é exiècia nas relacoés untre fualquer ker hamono, apticonolo o conherismento da sociolinguistica aue vis borra estudar a evolusaio da

Figura 3. Produção III

\section{Legenda:}

Texto escrito por um adulto estudante do $6^{\circ}$ período do Curso de Letras.

\section{Análise:}

O texto produzido por um aluno do $6^{\circ}$ período do curso superior de Letras surpreende pela quantidade e qualidade dos erros de grafia, tendo em 
vista o tempo de escolarização e a especificidade dos estudos realizados sobre a linguagem nesse campo de estudos. Além de questões sintáticas, como pontuação e concordâncias verbal e nominal, ocorrem erros de grafia como o mau emprego dos fonemas/grafemas $\mathrm{C} / \mathrm{C} / \mathrm{SS} / \mathrm{X}$, incorreção na diferenciação entre MAIS e MAS, omissão do R final e outras questões de sentido como em A TEORIA VARIACIONISTA O SUJEITO [...].

As análises dos textos produzidos por escribas de idades e níveis de escolarização diferentes apresentam questões bem próximas umas das outras, o que nos leva a inferir que todos permanecem no nível alfabético com falhas. A questão, porém, pode ser considerada como preocupante, sobretudo quando se trata de adultos (o traficante e o aluno de Sociolinguística do curso de Letras), que, apesar da idade e do grau de escolarização, ainda não desenvolveram certas capacidades necessárias à produção de uma escrita ortográfica.

\section{Considerações finais}

Brevemente, nesta pesquisa, apresentamos algumas questões acerca da ortografia e suas relações com os níveis de escrita. O que se quis afirmar é que o processo evolutivo de aprendizagem da escrita pode estagnar em níveis não ortográficos, o que leva o indivíduo a cometer erros de grafia.

Conforme expusemos, um adulto, embora alfabetizado - capaz de escrever e ser entendido por meio da escrita - pode transgredir as regras, caso não tenha desenvolvido suficientemente a capacidade metalinguística e o conhecimento das normas ortográficas, competências necessárias ao pleno domínio da escrita.

Nesse sentido, observam-se erros de escrita que podem ser caracterizados como hipóteses, os quais tomam por base a fala-escrita fonética -, ou seja, a não obediência à ortografia, bem como às regras morfossintáticas, o que geralmente acontece com crianças em período de alfabetização. É, portanto, nessa perspectiva, apropriado afirmar que as questões referentes à ortografia se originam no processo de alfabetização. 
Para um efetivo desenvolvimento da consciência metalinguística e o conhecimento das normas ortográficas, faz-se necessário um trabalho específico dos professores da alfabetização e de Língua Portuguesa, no sentido de chamar a atenção dos alunos para as peculiaridades da escrita, não somente exibindo regras, mas, sobretudo, aplicando práticas de observação mais atentas às questões etimológicas, fonéticas e morfológicas da língua.

\section{Referências}

ABAURRE, M.B. Dados da escrita inicial: indícios da construção da hierarquia de constituintes silábicos? In: Matzenauer C.L.B. (Org.). Aquisição de língua materna e de língua estrangeira. Pelotas: EDUCAT, 2001. ANTUNES, Irandé Costa. Muito além da gramática: Por um ensino sem pedras no caminho. São Paulo: Parábola, 2007.

BARBOSA, José Juvêncio. Alfabetização e leitura. São Paulo: Cortez, 1994. BARRERA, Sylvia Domingos. Papel facilitador das habilidades metalingüísticas na aprendizagem da linguagem escrita.In:MALUF, Maria Regina. Metalinguagem e Aquisição da Escrita.São Paulo: Casa do Psicólogo, 2003. P. 65-69.

BORTONI-RICARDO, Stella Maris. Nós cheguemu na escola e agora? Sociolinguística e educação. São Paulo: Parábola, 2005.

BRASIL. Base Nacional Comum Curricular. Ensino Fundamental. Brasília, MEC. Livro Eletrônico. Disponível em: http://basenacionalcomum.mec.gov. br/. Acesso em: 23 out. 2017.

BRASIL. Lei n. 9394, de 20 de dezembro de 1996. Estabelece as diretrizes e bases da educação nacional. Brasília, p. 36, 1996. Legislação Federal. In: Ministério da Educação. Parâmetros curriculares nacionais - adaptações Vol. 11 Número 22 Jul./dez. 2016 curriculares: estratégias de ensino para educação de alunos com necessidades educacionais especiais. Brasília: SEF; SEESP, 1999. 
CAGLIARI, Luiz Carlos. Alfabetização e Lingüística. São Paulo: Scipione, 2003.

FAYOL, Michel. Aquisição da escrita. São Paulo: Parábola Editorial, 2014. FERrEIRO, E.; TEBEROSKY, A. Psicogênese da língua escrita. Porto Alegre: Artes Médicas, 1986.

FERREIRO, E.; PALÁCIO, M. G. Os processos de leitura e escrita: novas perspectivas. Porto Alegre: Artes Médicas,1987.

GOMBERT, Jean Emile. Atividades metalinguísticas e aprendizagem de leitura. In MALUF Mari Regina. Metalinguagem e aquisição da escrita. São Paulo: Casa do psicólogo, 2003. P. 16-63.

GOMES Ana Lucia; CORREA Jane. Escrita teclada x escrita padrão na produção textual: a experiência de adolescentes brasileiros. $1^{\mathrm{a}} \mathrm{ed}$. Revista Portuguesa de Educação: 2009. P. 71 - 88. Disponível em: http://www.scielo. mec.pt/scielo.php?script=sci_arttext\&pid=S0871918720090001004. Acesso em: $21 \mathrm{dez}, 2019$.

KATO, Mary Aizawa. No mundo da escrita: uma perspectiva psicolinguística. São Paulo: Ática, 1986.

METODOLOGIA. Instituto Paulo Montenegro. Disponível em: https://ipm. org.br/inaf. Acesso em: 5 mar. 2020.

MORAIS, Artur Gomes de. Ensinando ortografia na escola.In:MORAIS, Artur Gomes de. Ortografia na sala de aula. Belo Horizonte: Autêntica, 2007. P. 61-76.

MORAIS, Arthur Gomes. Ortografia: ensinar e aprender. São Paulo: Ática, 2003.

QUEIROGA, B. A. M.; BORBA, D. M.; VOGELEY, A. C. Habilidades metalinguísticas e a apropriação do sistema ortográfico. Soc. Bras. Fonoaudiologia, São Paulo, 2004. 
SOARES, Magda. Alfabetização e letramento. São Paulo: Contexto, 2013.

SCLIAR-CABRAL, L. Da oralidade ao letramento: continuidades e descontinuidades. Porto Alegre:Letras de hoje, 1995.

VALE, Ana Paula; SOUSA, Otília. Conhecimento ortográfico e escrita. Braga: 2017.

ZORZI, J. Luiz. A Influência do Perfil de Leitor nas Habilidades Ortográficas. Rio de Janeiro: Soletras, 2003. 